During the next year the second question which I had attempted to solve, viz., the influence of temperatures above $100^{\circ} \mathrm{C}$., was taken up with much greater completeness by Prof. Gscheidlen, of Breslau. ${ }^{2}$ After a résumé of the proofs already given by his predecessors, that certain fluids are not sterilised by boiling; and, secondly, that as means of sterilising $\mathrm{such}$ Jiquids the action of prolonged exposure and that of increased temperature may be regarded as complementary to each other, he proceeds to relate his own researches, the purpose of which was rather to fill up defects in the evidence than to establish new conclusions.

The flasks employed were capable of containing roo cub. centims. (three and a half oz.); they were charged in the usual way with the turnip-cheese liquid, and exposed for short periods in chloride of calcium baths, of which the strengths were carefully adjusted so as to obtain the requisite temperatures. It was thereby definitely proved that whereas the germinal matter of Bacteria can stand a temperature of $100^{\circ}$ for five or ten minu es it is destroyed by temperatures varying from $105^{\circ}$ to $110^{\circ} .^{2}$

In an appendix to my first paper, publisked in NATURE in the autumn of 1873 , I showed that the solution of diffusible proteids and carbo-hydrates employed by Prof. Huizinga, of Groningen, in the first of the valuable series of experiments ${ }^{3}$ published by him, relating to the subject of spontaneous generation, require a temperature above that of ebullition under ordinary pressure to sterilise them. This observation has since been established by Prof. Huizinga himself on the basis of very carefully made experiments, ${ }^{4}$ by which he has proved at the same time that the liquids in question are rendered completely incapable of producing Bacteria without extrinsic contamination by exposing them to higher temperature. The only points of difference between us, either as regards method or result, are, first, that the sterilisation limit (Grenze zur Bacterienerzetugung) fixed by me was too low-the true limit being $110^{\circ}$ C.--and secondly, that the experiments from which $I$ had inferred that the liquids in question had been sterilised at lower temperatures than this were, in Prof. Huizinga's opinion, rendered inconclusive by the fact that my flasks were sealed hermeti-

tion notwithstanding that the results obtained were mere confirmations of those of formex observers; adding "tür den wissenschaftlichen Forischritt hat nicht die Priorität des eiuen oder des anderen Beobschters, wohl aber

hohe "Wichtigkeit."

Archiv, vol ix p. 163

2 "Es folgt aus den eben angegebenen Versuchen, nach meiner Meinung, dass in Huizinga's Gemengen die Bacterien einer Temperatur von $2 \times 0^{\circ} 5$ ro Minuten lang $\mathrm{zu}$ widerstehen vermögen, nicht aber einer von $\operatorname{Io}^{\circ} \cdot \times 10^{\circ}$ in eingeschmo!zenem *Iasrohre während der nämlichen Zeit" (loc. cit. p. I67). Here the author clearly fails to make the necessary distinction between Bacteria (which, as is well known, lose their vitality at a much lower temperature) and the material out of which they spring. The mixtures referred perature) and the mere either the cheese and turnip liquid or solutions containing peptones and grape sugar, to be inmediately referred to. As affording an elegant and grape sugar, to be inmediately refiquid it is the cheese and not any demer constitueas which contains the resistant element, the fol'owing form of other constitueat which contains - A tube A drawn out and closed at both exps is iused into the open mouth of a second tube $B$, of which the opposite ends is iused into the open mouth of a second tube B, of which the opposite end is dra tube is formed and $B$ A small knob of glass haviog been prensously introduced into the chamber B, the septum can be easily broken by shaking the tube. With tubes so prepared two experimests are made. ment $A$ is charged with infusion of cheese, sealed., and then exposed to a temperature of $110^{\circ}$ before it is united to the compartment B. In like manner B is charged with neutral decoction of turnip, so that when the compound tube is complete it contains cheese in one compartment. turnip in the other. If, after boiling for ten minutes, it is placed in the warm chamber its contents remain barren. In Experiment 2 the experiment is varied by simply omitting the preliminary heating of A. The compound tube is bjiled as before, but now its contents promptly give evideace that the conditions are presene for an abundant development of Bacteria.

3 Prof. Huzingas papers on the Question of Abiogenesis are four in number. 'The references are as follows:-Pfiiger's Archiz', vol, vii. p. 225, vol. viii. pp 180,551 ; vol. x. p. 62

4 The solution employed in these experiments was neutral, and contained, in addition to the requisite inorganic salts, 2 per cent. of grape suzar, o per cent. of soluble starch, 03 per cent. of peptones, and I per cent. ammonic tartrate. As in my experiments, the flasks were heated in a Papin's pot, of which the temperature was ${ }_{102}{ }^{\circ} \mathrm{C}$. Even after half an hour's exposurc to this temp $\rightarrow$ rature all the flasks became in two or three days "stark trübe und voll Bacterien," third paper, p. 555, January, 187 cally, whereas in his exchange of air was allowed to take place during the period of incubation, through a septum of porous porcelain. To this last objection I might perhaps have thought it my duty to answer, had it not been shown by the subsequent researches of Gscheidlen to have no bearing on the question at issue. As regards the limit of sterilisation I can entertain no doubt as to the accuracy of Huizinga's measurements, and am quite willing to accept $108^{\circ} \mathrm{C}$. as the lowest temperature which could be safely employed under the conditions laid down by him.

It will be understood that in bringing these facts before the Society my only purpose is to show, as I trust I have done conclusively, that the statements which Dr. Tyndall in 1876 characterised as incautious, and which he virtually invited me to retract, had been two years before confirmed in every particular by experimenters of acknowledged competence.

\section{DIFFUSION FIGURES IN LIQUIDS}

$\mathrm{T}$ making some experiments on the mixture of liquids 1 entering into another liquid at the extremity of a tube of small diameter, a phenomenon presented itself which attracted my attention as both new and singular. A certain quantity of coloured alcohol, remaining in suspension in the centre of a body of water, assumed, by spreading gradually out, a form resembling that of a shrub having its trunk and its branches terminated by leaf-like expansions. I sought to reproduce the pheno-

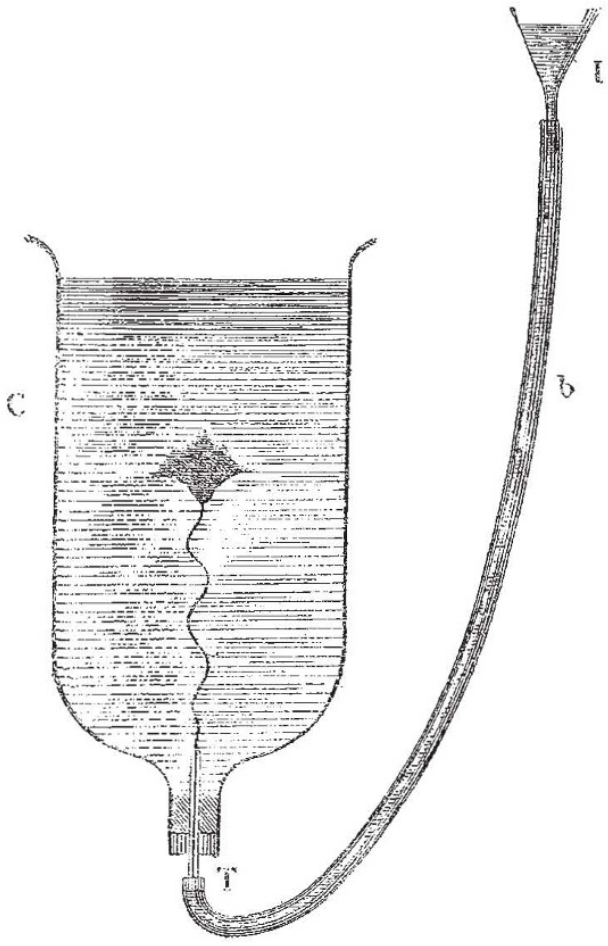

FIG. x. -Apparatus of Prof. Martini.

menon, believing at first that this mode of diffusion was purely accidental ; but the phenomenon always recurring very nearly in the same manner, I devised a mode of experimenting which enabled me to study it more advantageously.

C (Fig. 1 ) is a sort of cylindrical funnel of glass, to the neck of which is fitted a small capillary thermometrical tube $T$, about eight centimetres long. The capillary tube communicates by means of a caoutchouc tube $a b$, with a

I From au article in La Nature by Prof. Tito Martini, of Venice. 
small funnel $\mathrm{r}$, which may be raised or lowered at pleasure by means of its support. Pour into 1 a certain quantity of alcohol coloured say with a red solution of aniline. The liquid will traverse the capillary tube, from which it will flow unless prevented by compressing the india-rubber tube with a small pincers. This being done, fill with water the vessel $\mathrm{C}$ about three-fourths full; then by means of a funnel whose lower extremity reaches a little below the middle of the water, introduce a liquid denser than water, a concentrated solution of sea-salt or a thick syrup, until the vessel is filled up. Sulphuric acid may also be used, and in that case a less volume of liquid will suffice.

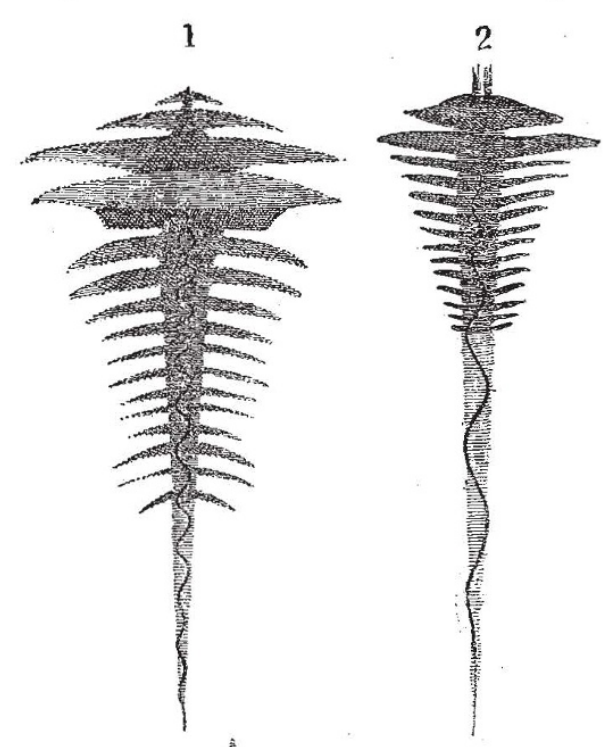

3

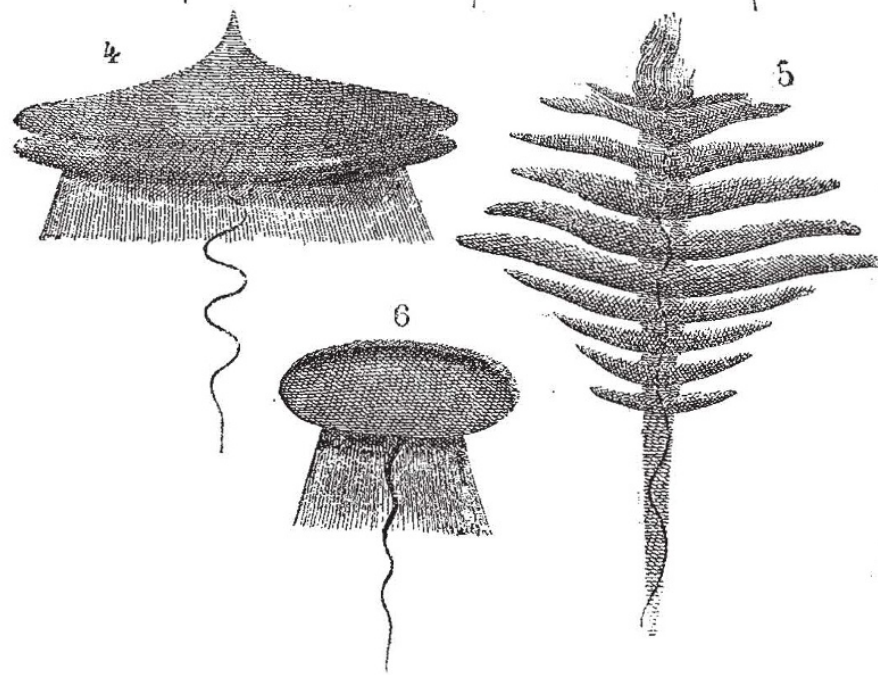

FIG. 2.-Experiments of Prof Martini on the diffusion of coloured liquids in: a sirupy liquid.

The liquid more dense than water will collect at the bottom of $\mathrm{C}$; and there will thus be two layers of liquid superposed, the exact separation of which may be observed after being allowed to stand for an hour. If at the end of that time we raise the funnel I to a suitable height and relieve the pincers which compress the tube $a b$, the coloured alcohol which flows from the extremity of the capillary tube will enter the liquid in the vessel $C$, forming an ascending vein which usually has a spiral form. The alcoholic vein traverses the thickest layers of the liquid and is stopped at the boundary which separates the denser from the less dense part which floats above. At the point where the column of coloured alcohol is arrested, it will be seen to agglomerate into a mass at first formless ; but, gradually, that mass elongates and extends. then is seen to throw out fluid threads in the form of foliage, sometimes similar to the petals of a flower, sometimes analogous to the leaves of a tree. After an hour the coloured alcohol has assumed a stable and regular figure. That figure varies in form with the liquids employed; it sometimes resembles a flower, sometimes a shrub, and sometimes it takes the form of a parasol of bright and vaporous colours, which add to its beauty.

The figure, so far as its form is concerned, attains its maximum of development three hours or more after the fluid vein begins to flow; but after that time the leafy expansions dilate more and more, and approach each other so as to form a mass of con'inuous layers, which remain suspended in the midst of the liquid. This happens even when the inflow has been arrested, either by applying the pincers to the india-rubber tube, or even by lowering suitably the funnel, I. It should also be remarked that around the vein of ascending liquid there very often forms a very fine tube, which assumes the aspect of the stalk of the flower, or rather the trunk of the liquid shrub; from different points of that stalk expansions in the form of leaves will be seen to proceed.

In order that the experiments I have devised may be successful, the tube through which the coloured liquid enters the vessel ought to be capillary, the flow ought to be gentle, and the apparatus maintained in a state of complete rest. It is necessary, moreover, to be careful first to expel the air from the india-rubber tube, since air-bubbles disturb the formation of the phenomenon. The following is a succinct résumé of some of the results I have obtained with different liquids :-

Colours of Aniline Solution.-I made use of aniline red, brown, green, and violet, dissolved in alcohol, being careful that the solution was not too concentrated. The forms obtained in sugared, salted, and acidulated water, are those represented in Fig. 2, Nos. I and 2. The figures obtained resemble, as will be seen, leaf-like expansions; the ramifications are turned downwards in sugared water (No. I); in salt water, on the contrary, they are always raised, and at the commencement even more so than is shown in the figure. When acidulated water is used, the aniline colours are modified by the action of sulphuric acid; the green becomes pale yellow, the red becomes brown, and the violet acquires a beautiful green colour; but in all cases the shrub-like figure No. 2 is formed with perfect regularity.

Litmus. Aqueous Solution.-With this solution we obtain in acidulated water the figure represented in No. 3 (Fig. 2), which resembles a small parasol. Looked at from above, it has the aspect of a disc from the periphery of which proceed many equidistant rays very close to each other. In the salt water the same aqueous solution gives a different figure. In general, when aqueous solutions are employed to form the figures a space of time is required longer than that which is necessary in the case of alcoholic solutions.

Alcoholic Solution. - With this solution there are formed in salt or sugared water, figures analogous to Nos. I and 2 ; in acidulated water there is produced a shrubby appearance similar to No. 2.

Lake.-The aqueous solution of lake forms in salt water a figure similar to that of No. 4; in acidulated 
water Fig. 3 is produced, but more delicate and more regular than that obtained with litmus.

Azure Blue.-The aqueous and alcoholic solutions of azure-blue or pearl form figures similar to those already described. In acidulated water we obtain a very regular spheroidal nucleus of a very dark blue, surrounded by a spheroidal layer with an inferior stem (No. 6).

Cochineal.- The aqueous solution forms in acidulated water the figure No. 3, regular, like that of litmus and of lake. In salt water, cochineal, not being soluble, is precipitated and the phenomenon is not produced.

Iodine.-The alcoholic tincture of iodine forms, in sugared, salt, or acidulated water, beautiful figures almost identical with those of the colours of the aniline solution.

Bichromate of Potash.-To make the experiments with bichromate of potash succeed I changed the arrangement of the experiment on account of the very great density of the solution in comparison with the density of water. I fill the vessel in the usual manner, then I place above the vessel a small funnel, fitted with a capillary tube which partly enters the liquid. The aqueous solution of bichromate of potash being poured into the small funnel, flows out, forming a small descending spiral, which usually is arrested in the division between the more and less dense parts of the liquid. In acidulated or salt water two very beautiful figures are formed resembling those of Nos. 2 and 5 , but reversed.

The various experiments described above have been repeated several times for each colour, and I have always obtained the same results. This persistence of form shows that the phenomenon is regulated by a law which I shall seek to discover. I believe I may conclude from these first attempts that the form of the figure depends on the liquid in which the colour is dissolved, more than on the colour itself. By employing other acids and other salts, not such, however, as precipitate the colour, it is probable that other figures would be obtained.

\section{TRACES OF EARLY MAN IN YAPAN}

$\mathrm{SO}$ much interest is felt in the origin of the Japanese, $D$ that any information regarding earlier races in Japan will interest the readers of NATURE.

The discovery and examination of a genuine kjockkenmoedding, or shell heap, enables me to give positive evidences regarding a prehistoric race who occupied this island. Whether autocthonous or not it would of course be impossible to say. On my first ride to Tokio, in June of this year, I observed, from the car window, near a station called Omori, a fine section of a shell heap, which was recognised as such at once, from its resemblance to those I had often studied along the coast of New England. On September 16, accompanied by Messrs. Matsumura, Matsura, and Sasaki, three intelligent Japanese students, I made an examination of it, and a few days afterwards, in company with Dr. David Murray, Superintendent of Public Instruction, and Mr. Vukuyo, with two coolies to do the heavy digging; made an exhaustive exploration of it.

The deposit is composed of shells of various genera, such as Vusus, Eburna, Turbo, Pyrula, Arca, Pecten, Cardium, two strongly marked species of Ostrea, and curiously enough, Mya arenaria, not to be distinguished from the New England form, as well as other genera. These shells, so far as I know, still live in the Bay of Yedo. The heap is about 200 feet wide, and varies from a foot to five or six feet in thickness, with a deposit of earth above, at least three feet in thickness. It is now nearly half a mile from the shore of the Bay, though in accordance with the usual position of these heaps in other parts of the world, it must have been formed near the shore, and this fact indicates a considerable elevation of the land since the deposits were made. I may add that other evidences of a geological nature indicate a wide-spread upheaval in past times.

The peculiarities of the typical shell-heap, such as fragments of bones, rough implements worked out of horn, and pieces of pottery, are all here. The heap, however, is marked by certain features which render it peculiar.

First, the immense quantity of pottery and its diversity of ornamentation, some of it extremely ornate, but very rude.

Second, the absence of bone-implements, the few found-eight or ten in number-being of horn, with the exception of an arrow-head of diminutive proportions, made of the tusk of a wild boar. All the implements are very simple ; two of them are like blunt bone awls, with the end very obtuse, and a constriction worked around the end. Another one is made from the natural termination of a deer's antler. A few fragments of horn were found which had been cut off at the ends.

Third, the entire absence of flint flakes, or stone implements of any kind, if we except a small stone adze found near the top of the heap, and made out of a soft sandstone. The frequent occurrence of isolated tusks of the wild boar would seem to indicate that these teeth were used for implements, and one piece of antler, having a hole in the end, is worked in the form of a rude handle. By far the most common bones found were those of the deer and wild boar, and curiously enough Steenstrup shows the same proportion in the Danish shell heaps. No human bones have yet been found.

An analysis of the red pigment found on some of the pottery shows it to be cinnabar. With its removal from the shore, its elevation above the level of the sea, the absence of stone implements, and the great thickness of the earth deposits above, we have reasons for believing that the deposit is of high antiquity.

Through the intelligent interest manifested by $\mathrm{Mr}$. Kato and Mr. Hamao, Director and Vice-Director of the Imperial University of Tokio, every facility for a thorough investigation of these deposits will be given me.

Tokio, Japan, September 2 I EDWARD S. Morse

\section{NOTES}

IT is proposed to hold the next annual meeting of the Asso. ciation for the Improvement of Geometrical Teaching (under the presidency of Dr. Hirst) at University College, Gower Street, on January II, I878, at 10.30 A.M. Four resolutions are to be submitted to the Association:-1. That in the opinion of this Association it is both reasonable and expedient that candidates at all examinations in elementary geometry should be required to give evidence of such ability as is necessary for the solving of easy geometrical exercises; and that the secretaries of the Association be instructed to send a copy of this resolution to the leading examining bodies of the country. The other resolutions relate to the proposed formation of sub-committees for drawing up a syllabus of (I) Solid Geometry, (2) Higher Plane Geometry (Transversals, Projection, \&c.), (3) Geometrical Conics. It may be in the recollection of our readers that the report of the British Association Committee (in 1876 , published at the time in NATURE), was highly favourable to the work of this Association.

THE dissection of the Berlin gorilla was performed last week by Prof. Virchow and Prof. Hartmann in the presence of several prominent Berlin physicians, and it was ascertained that the sudden death of the animal was caused by acute inflammation of the bowels, the same disease which carries off young children so rapidly. The dissection explains the cause of his previous illnesses and supplies valuable information with regard to the treatment of anthropoidal apes. The button of a glove, iron wire, and pins were found in Pongo's stomach. 